\title{
ESTADO DA ARTE E CONTRIBUIÇÃO DAS GEOCIÊNCIAS PARA EDUCAÇÃO AMBIENTAL
}

\author{
Eliana Mazzucato ${ }^{1}$ \\ Denise de La Corte Bacci ${ }^{2}$
}

\section{Resumo}

Este artigo apresenta o estado da arte das pesquisas na interface da Educação Ambiental e das Geociências. O mapeamento e as análises realizaram-se a partir do banco de teses do Projeto EArte, no período de 1981 a 2012. Identificaram-se 25 estudos, sendo analisados considerando os termos descritivos e seus resumos. Os resultados apontam para uma área em consolidação, definindo-se três categorias temáticas a partir das análises. $\mathrm{Na}$ primeira categoria há ênfase no conhecimento sobre o ambiente físico como contributo para ações de Educação Ambiental e estratégias de conservação; a segunda estimula a inserção dos conteúdos geocientíficos em ambientes escolar e não escolar, por meio de estratégias de divulgação na linha dos projetos de Educação Ambiental; a terceira refere-se a pesquisas em espaços de educação formal com perspectiva socioambiental. Essa revisão forneceu um esboço das principais abordagens das pesquisas, indicando caminhos e reflexões que unem essas duas áreas do conhecimento.

Palavras-chave: Educação ambiental. Geociências. Estado da arte.

\section{STATE OF ART AND CONTRIBUTION OF GEOSCIENCES FOR ENVIRONMENTAL EDUCATION}

\begin{abstract}
This article presents the state of art of research approaching Environmental Education and Geosciences. Mapping and analyses were carried out based on the thesis database of EArte Project, in the period from 1981 to 2012 . We identified and analyzed 25 studies, considering descriptive terms and abstracts. The results indicate a knowledge under consolidation, with definition of three thematic categories based on analyses. The first category emphasizes knowledge about the physical environment as a contribution to Environmental Education actions and conservation strategies; the second stimulates the insertion of geoscientific contents in school and non-school environments through dissemination strategies in line with Environmental Education projects; the third refers to research in formal education spaces with a socio-environmental perspective. This review provided an outline of the main research approaches, indicating the paths and reflections that unite these two areas of knowledge.
\end{abstract}

Keywords: Environmental education. Geosciences. State of art.

\footnotetext{
${ }^{1}$ Mestre em Geociências, Universidade de São Paulo.

2 Professora Doutora do Departamento de Geologia Sedimentar e Ambiental, Instituto de Geociências, Universidade de São Paulo.
} 


\section{ESTADO DEL ARTE Y CONTRIBUCIÓN DE LAS GEOCIENCIAS PARA LA EDUCACIÓN AMBIENTAL}

\section{Resumen}

Este artículo presenta el estado del arte de las investigaciones que abordan temas como la Educación Ambiental y las Geociencias. El mapeo y análisis de datos se llevó a cabo durante el periodo comprendido entre 1981 a 2012, a partir del banco de datos del Proyecto EArte. Se identificaron y analizaron 25 estudios, considerando términos descriptivos y resúmenes. Los resultados indican un conocimiento en consolidación, con la definición de tres categorías temáticas a partir del análisis de datos. La primera categoría enfatiza el conocimiento sobre el ambiente físico como una contribución a las acciones de Educación Ambiental y a las estrategias de conservación; la segunda estimula la inclusión de contenidos geocientíficos en ambientes escolares y no escolares, a través de estrategias de transmisión ligadas con proyectos de Educación Ambiental; la tercera se refiere a la investigación en espacios de educación formal con una perspectiva socioambiental. Esta revisión proporcionó un esbozo de los principales enfoques de investigación, revelando los caminos y vínculos que unen estas dos áreas de conocimiento.

Palabras clave: Educación ambiental. Geociencias. Estado del arte.

\section{Introdução}

O diálogo entre a Educação Ambiental e as Geociências tem se revelado como um novo caminho de pesquisas e práticas evidenciando a interface entre essas duas áreas do saber. Nesse encontro, as relações se dão a partir da atual crise ambiental, demandando novas formas de olhar para a complexidade na qual os problemas socioambientais estão constituídos. O conhecimento acerca do planeta Terra pode ser um ponto de partida para compreender essa complexidade. Diante das possibilidades de caminhos e concepções da Educação Ambiental, faz-se necessário analisar as pesquisas que integram as Geociências a este campo.

As Geociências ou Ciências da Terra se referem ao conjunto de disciplinas ou especialidades científicas que buscam compreender a Terra, sua dinâmica e processos naturais. Dessa forma, é o escopo de um leque de disciplinas como Geologia, Geofísica, Oceanografia e Meteorologia. Além dessas, mantêm relação estreita com a Geografia e as técnicas empregadas nas engenharias (CORDANI, 1995).

Como destacou Cordani (1995), essa área do conhecimento se dedica a determinadas temáticas que são cruciais para pensar a sustentabilidade. A primeira delas é o "Monitoramento do Sistema Terra", que analisa fenômenos como o aquecimento global a partir da dinamicidade do planeta e suas flutuações climáticas em escala de tempo geológico. As duas temáticas seguintes referem-se à "Busca, Gerenciamento e Fornecimento de Recursos Minerais e de Recursos Energéticos”, que fomentam a minimização dos impactos causados pela mineração e pela geração de energia elétrica e promovem pesquisas por fontes alternativas de energia. Além disso, destacou a "Conservação e Gerenciamento de Recursos Hídricos e dos Solos Agrícolas", que são bases para o desenvolvimento das atividades humanas e produção de alimentos. Por fim, indicou as pesquisas geocientíficas para a "Redução dos Desastres Naturais".

Como afirmam Finley, Nam e Oughton (2011) na Ciência do Sistema Terra a complexidade ganha maior espaço. Os autores consideram essa ciência como "o estudo dos 
sistemas naturais e sociais e as interações entre esses sistemas" (FINLEY; NAM, OUGHTON, 2011, p. 1.067).

Portanto, o conceito de Ciência do Sistema Terra incorpora o olhar sistêmico, encontrando amparo nos estudos que valorizam as questões ambientais e os problemas de riscos naturais nos estudos terrestres (CARNEIRO et al., 2005). Como destacam Piranha e Carneiro (2009), essa abordagem vem ao encontro da noção de sustentabilidade e das análises das inter-relações homem/meio.

Modernamente denominada Ciência do Sistema Terra integra as diferentes esferas em que a matéria se organiza e nas quais todas as formas de energia provocam mudanças à medida que são permutadas. Esta condição permite, de forma peculiar, reconhecer o significado da ação humana no planeta, o que parece ser, no momento, questão central da ideia de sustentabilidade (PIRANHA; CARNEIRO, 2009, p. 131).

Nesse contexto de considerar as interações entre sistemas naturais e sociais e os impactos decorrentes da atividade humana na Terra e na atmosfera em escalas globais, Crutzen e Stoermer (2000) enfatizam o papel central da humanidade na geologia e na ecologia, propondo o termo Antropoceno para designar a atual era geológica, evidenciando que esses impactos terão continuidade por longos períodos de tempo. Assim, os seres humanos são reconhecidos como agentes geológicos e geomorfológicos, apresentando um papel importante na transformação da paisagem (PRICE et al., 2011).

Compiani (2005) discute a importância do ensino de Geociências desde o ensino básico, pois ele contribui com o desenvolvimento cognitivo das crianças, inserindo aspectos próprios dessa área do saber. Exemplo disso são as noções de escalas e de tempo geológico, a relação de causalidade, a narrativa histórica e interpretativa, além de proporcionar uma visão mais abrangente da natureza, superando a concepção antropocêntrica. A metodologia do trabalho de campo é recorrente no ensino de Geociências, pois desempenha papel na compreensão da dinâmica física do ambiente, possibilitando assim uma abordagem interdisciplinar para a contextualização socioambiental. Esses aspectos influenciam a formação moral e ética do sujeito, relativa à crise socioambiental.

Apesar disso, os conhecimentos específicos das áreas de Geociências ainda são pouco valorizados na dinâmica educacional do Brasil. Na educação formal os conteúdos referentes ao planeta Terra e seus elementos físicos são contemplados nas disciplinas de Geografia e Ciências no ensino básico, porém de forma fragmentada e superficial. Discute-se amplamente sobre a necessidade de maior e melhor formação em Geociências desde as séries iniciais e, também, da introdução da perspectiva dessa área do saber na concepção interdisciplinar da Educação Ambiental (BACCI, 2015).

$\mathrm{Na}$ Educação Ambiental, o ensino de Geociências contribui para a interdisciplinaridade e a abordagem sistêmica, assim, também podendo contribuir com suporte aos profissionais e professores que integrem projetos de Educação Ambiental, explorando, ainda, as possibilidades das metodologias do trabalho de campo ou estudo do meio (COMPIANI, 2013; 2015).

As Diretrizes Curriculares Nacionais para a Educação Ambiental (BRASIL, 2012) ressaltam o papel da contextualização dos conhecimentos no qual a dinâmica da natureza é compreendida segundo esta visão mais abrangente e holística, destacando em suas diretrizes gerais

Abordagem crítica dos aspectos constituintes e determinantes da dinâmica da hidrosfera, atmosfera, biosfera, sociosfera e tecnosfera, contextualizando os conhecimentos a partir da dinâmica da paisagem, da bacia hidrográfica, do bioma, do clima, dos processos geológicos, das ações antrópicas e suas interações, 
analisando os diferentes recortes territoriais, cujas riquezas e potencialidades, os usos e os problemas devem ser identificados e valorados (BRASIL, 2012).

As pesquisas que associam a Educação Ambiental às Geociências têm como ponto de partida a contribuição que o conhecimento sobre o Sistema Terra oferece em relação ao esclarecimento das questões ambientais, de forma a contribuir para a formação de cidadãos mais comprometidos com a sustentabilidade. Bacci e Boggiani (2015) revelam que a carência de conteúdos geocientíficos no ensino básico tem provocado uma visão distorcida ou até mesmo errônea de ambiente pela sociedade como um todo. Isso resulta na incapacidade de lidar com problemas complexos, como a expansão urbana sobre áreas irregulares e de risco, falta de planejamento quanto aos recursos hídricos e até mesmo a contaminação dos aquíferos e a exploração de recursos minerais.

Para Bacci (2015), é importante reconhecer que as Geociências estão presentes no cotidiano dos cidadãos, oportunizando que a sociedade apreenda a relação entre a dinâmica natural e a melhoria da qualidade de vida e, assim, possa tomar decisões. Dessa forma, é reforçada a dinâmica socioambiental que encerra uma forma de ver o mundo, um olhar integrado sobre o meio físico e social.

Santos (2011) enfatiza a necessidade da construção do olhar geocientífico nas escolas, proporcionando o (re)conhecimento do lugar, ou seja, uma apreensão crítica da realidade socioambiental local, onde o estudo do e no ambiente toma sentido e significado para as pessoas. A autora reforça a concepção de ambiente como espaço construído e destruído a partir da interação sócio-histórica, entre sociedade e ambiente. Portanto, a interface das Geociências com a Educação Ambiental emerge da compreensão crítica da realidade socioambiental que requer a percepção da dinâmica física do lugar, permeando assim o diálogo entre as Ciências da Terra e as Ciências Sociais (SANTOS, 2011).

Nesse panorama ressalta-se a multiplicidade de abordagens presentes na Educação Ambiental. Silva (2007) propõe uma tipologia para concepções de Educação Ambiental, fornecendo uma seleção de elementos que ajudam a inferir a Educação Ambiental abordada, podendo se tratar de Conservadora, Pragmática e Crítica.

A Educação Ambiental Conservadora remete ao ideário romântico do movimento preservacionista do século XIX. Nessa perspectiva, há uma visão dicotômica da relação homem e natureza, em que o homem toma um posicionamento destrutivo nessa relação. Há pouca abordagem a respeito das causas mais profundas dos problemas ambientais, e quase não há referências às questões políticas e sociais (SILVA, 2007).

A Educação Ambiental Pragmática orienta-se no sentido da resolução de problemas, dando ênfase às regulamentações, normas e diretrizes. A difusão de informações para a mudança de comportamentos também é uma linha de atuação. Nessa abordagem procura-se compatibilizar o desenvolvimento econômico ao uso sustentável dos recursos e discute-se a cidadania e as questões ambientais (SILVA, 2007).

A Educação Ambiental Crítica insere-se numa perspectiva mais complexa da relação sociedade-natureza, busca o fortalecimento da sociedade, reflexiva e mobilizada para a busca de soluções coletivas e transformadoras para se tornar mais sustentável. Nesse caso, as questões políticas e sociais ganham maior centralidade (SILVA, 2007).

Nessa direção, este trabalho apresenta o levantamento das pesquisas desenvolvidas no âmbito da pós-graduação do Brasil na interface entre as Geociências e a Educação Ambiental a partir do banco de dados do Projeto EArte (Estado da Arte da Pesquisa em Educação Ambiental). Além de reunir o acervo bibliográfico sobre a temática, buscou-se compreender como essas pesquisas foram desenvolvidas quais suas concepções e metodologias, e como ocorreu essa interface. 


\section{Metodologia de pesquisa}

O levantamento da pesquisa teve como fonte de dados o acervo de dissertações e teses brasileiras em Educação Ambiental (BT\&D/EA) desenvolvido pelo Projeto EArte. Essa escolha deve-se ao fato de o projeto ser referência no levantamento bibliográfico sobre Educação Ambiental em nível nacional, sendo um panorama confiável e de fácil acesso para o desenvolvimento de pesquisas sobre estado da arte.

O EArte reúne publicações acadêmicas desenvolvidas entre 1981 e 2012. Elas estão inseridas em um catálogo eletrônico ${ }^{3}$ contendo uma ficha de classificação de acordo com os descritores definidos pelo projeto. Cada ficha possui informações sobre pesquisador(a), instituição, orientador(a), ano de defesa, resumo e palavras-chave, além de outros dados, por exemplo, sobre o contexto educacional (escolar, não escolar, abordagem genérica) e o tema de estudo.

Os critérios de seleção usados neste trabalho foram definidos com a finalidade de buscar pesquisas em Educação Ambiental que apresentassem em seu contexto relações com as Geociências. Desse modo, optou-se por inserir no ambiente de busca os seguintes descritores: Geociências, Ciências da Terra, Ciência do Sistema Terra e Geodiversidade. Cada um desses termos foi inserido na opção de "qualquer campo" da busca para alcançar a maior abrangência possível das pesquisas em Geociências.

A busca a partir dos critérios estabelecidos foi realizada em 2016, identificando ao todo 30 pesquisas. Diante desse resultado preliminar, foram necessários alguns refinamentos para exclusão de trabalhos que, apesar de aparecerem na seleção, não faziam parte do escopo desta pesquisa. Esse procedimento resultou na retirada de cinco trabalhos, considerando as seguintes justificativas: foi verificado um caso em que o mesmo trabalho apareceu duplicado no sistema de buscas; dois casos em que os trabalhos eram da área de matemática provavelmente constavam na busca por fazer parte do Instituto de Geociências e Ciências Exatas. Outras duas pesquisas foram retiradas a partir da leitura dos resumos, pois não demonstraram aspectos relativos às Geociências. A primeira referia-se a um projeto sobre coleta seletiva no qual o Instituto de Geociências apareceu como local de coleta de dados, e a segunda analisava projetos de Educação Ambiental de uma empresa portuária.

A análise ocorreu de forma qualitativa, a partir da leitura dos resumos dessas 25 pesquisas, buscando delinear um panorama geral e ressaltar suas tendências futuras. Apesar da análise dos resumos não garantir uma abordagem aprofundada e homogênea, estes constituem importantes fontes devido à dificuldade de acesso de trabalhos completos, muitas vezes disponíveis em bibliotecas físicas dos institutos.

\section{Panorama dos Programas de Pós-Graduação em Geociências e Educação Ambiental no Brasil}

A avaliação do Sistema Nacional de Pós-Graduação pela Coordenação de Aperfeiçoamento de Pessoal de Nível Superior (Capes), realizado em 2016 (BRASIL, 2016), apontou a existência de 56 Programas de Pós-Graduação em Geociências no Brasil. Destacam-se como subáreas nesses programas as Ciências Atmosféricas, Ciências Geodésicas, Ciências Geofísicas, Ciências Geológicas e Ciências Oceanográficas.

Grande parte dos cursos se concentra em instituições públicas de ensino superior $(95 \%)$, com apenas $5 \%$ em instituições de natureza não pública (3 programas). Em relação à localização, vê-se uma assimetria entre as regiões do país, sendo que 44,6\% dos programas

\footnotetext{
${ }^{3}$ Disponível em: <http://earte.net/>. Acesso em: 21 jul. 2016.
} 
estão concentrados na região Sudeste (25 programas). A região Nordeste possui $25 \%$ (14 programas) e o Sul, 16,1\% (9 programas). Os menores índices correspondem às regiões Norte, com 8,9\% (5 programas) e Centro-Oeste, com 5,4\% (3 programas) (BRASIL, 2016).

Segundo a mesma avaliação, o número de programas de pós-graduação em Geociências apresenta similaridade com o número de cursos de graduação nas subáreas indicadas. Apesar de apresentar um crescimento lento de programas nos últimos 20 anos (de 1996 a 2016 houve o incremento de 65\% de programas na área), identificou-se que a partir de 2000 houve um revigoramento nesse processo. Isso pode estar associado ao crescente reconhecimento do caráter interdisciplinar das Geociências, proporcionando um movimento de revitalização e incremento em pesquisas e programas na pós-graduação nesse campo do saber. Verifica-se assim o aumento na interação com outras especialidades científicas e em estudos de meio ambiente.

Portanto, as Geociências, recorrendo aos conhecimentos, métodos e técnicas próprios das várias ciências, se ocupam em elucidar a complexidade dos sistemas, os fenômenos naturais e o caráter das relações que os mesmos estabelecem com os sistemas humanos (BRASIL, 2016, p. 11-12).

O panorama apontado no documento da Capes (BRASIL, 2016) em relação à inserção/incidência das Geociências no ensino fundamental e médio indica um crescente interesse nessa aproximação, que tem ocorrido por meio de formação de professores e de cursos de atualização. Além disso, as instituições de ensino superior (IES) oferecem programas que propiciam essa interação com visitas guiadas a laboratórios, museus, oficinas, feiras de ciências, palestras e exposições. Assim, os indicadores se pautam em programas de iniciação científica júnior e no desenvolvimento de materiais didáticos para a educação básica.

$\mathrm{Na}$ pós-graduação, alguns programas já incorporam o estudo do ambiente e/ou a educação em suas linhas de pesquisa, fornecendo indicativos para a consolidação dessas pesquisas que serão destacados nesse contexto.

A Universidade Estadual de Campinas (Unicamp) foi palco da institucionalização das pesquisas em Educação e Geociências, sendo que em 1996 foi incluída a área de concentração em Educação Aplicada às Geociências no Programa de Pós-Graduação em Geociências, resultado das ações de uma área de estudos de mesmo nome criada em 1979. Em 2004, foi criado o Programa de Pós-Graduação em Ensino e História das Ciências da Terra, com objetivos pautados na educação, cultura geocientífica e na divulgação destes conhecimentos (UNIVERSIDADE ESTADUAL DE CAMPINAS, 2016).

Outro caso relevante é o da Universidade Estadual Paulista (Unesp), que possui o Programa de Pós-Graduação em Geociências e Meio Ambiente. A implementação deste remete à criação da área de concentração em Análise Ambiental em 1986, período em que não havia similar na pós-graduação do Brasil, destacando o papel do geocientista para contribuir com a solução da problemática ambiental (UNIVERSIDADE ESTADUAL PAULISTA, 2016).

Destacam-se também programas de pós-graduação com linhas de pesquisa em Geologia Ambiental, que constituem importantes referências para a interface das geociências e dos estudos ambientais.

Em nível de graduação, foi criado em 2003 o curso de Licenciatura em Geociências e Educação Ambiental na Universidade de São Paulo (USP). Esse curso incide numa proposta de "complementar o ensino de Ciências Naturais com conteúdos geológicos, somados a conteúdos de Biociências e a conteúdos da Geografia" (TOLEDO et al., 2005, p. 3). Para Bacci e Boggiani (2015, p. 22), essa proposta "contempla uma formação crítica em relação às 
questões educacionais e socioambientais", sendo que sua visão sistêmica deve contribuir com atividades interdisciplinares de Educação Ambiental.

Em 2004, foi criado o curso de Ciências da Natureza, na Escola de Artes, Ciências e Humanidades (EACH) na USP. Possui o objetivo de formar professores de Ciências para o ensino fundamental abrangendo conteúdos relativos às Ciências Naturais, Matemática e Pedagogia (ESCOLA DE ARTES, CIÊNCIAS E HUMANIDADES, 2012).

\section{Mapeamento das Pesquisas em Geociências e Educação Ambiental}

O mapeamento das pesquisas decorreu de 2.763 trabalhos em Educação Ambiental no Brasil constantes do banco de dados do Projeto EArte. Esta pesquisa realizou o recorte temático de 25 dissertações e teses. Assim, do total de 2.763 trabalhos disponibilizados em 2016, aproximadamente 1,11\% correspondem às pesquisas de Educação Ambiental e Geociências a partir dos critérios estabelecidos.

As pesquisas mais antigas em Educação Ambiental presentes no acervo são de 1981, sendo elas: Nobre (1981), Pernambuco (1981) e Lima (1981). Em contrapartida, a primeira pesquisa em Educação Ambiental no âmbito das Geociências é a dissertação de Carvalho (1995). Portanto, somente depois de 14 anos o olhar geocientífico aparece ligado de forma mais expressiva ao campo da Educação Ambiental. Observa-se assim a contemporaneidade presente nas pesquisas que apresentam essa interface estimulando a formulação de alguns questionamentos como: o papel das Geociências para a Educação Ambiental é reconhecido pela comunidade acadêmica? Como as Geociências têm contribuído para a Educação Ambiental no Brasil?

A partir dessas questões, seguiu-se a algumas análises qualitativas desse conjunto, considerando os resumos e as fichas de catalogação do EArte. O Gráfico 1 refere-se ao número de pesquisas desenvolvidas entre 1981 e 2012 nesse recorte temático. As pesquisas relativas a 2010 não estão inseridas no EArte, pois os dados referentes a esse ano não foram disponibilizados pelo banco de teses e dissertações da Capes.

É possível observar no Gráfico 1 que as publicações nessa área ocorreram a partir de 1995, compondo 17 anos de produção. Ressalta-se que a partir de 1995 ocorreram períodos sem produção acadêmica, somando um total de sete anos sem a conclusão de dissertações ou teses (período de 1996 a 1998, de 2001 a 2002, 2004 e 2007).

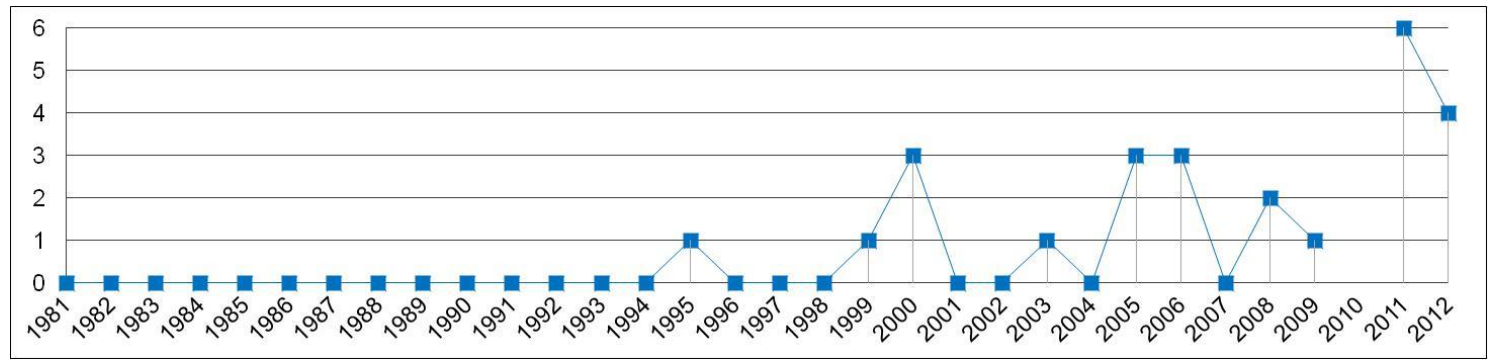

Gráfico 1 - Evolução da produção de dissertações e teses em Educação Ambiental e Geociências entre 1981 e 2012

Fonte: Elaborado a partir do EArte.

O quadro geral da evolução dessas pesquisas aponta para um crescimento nos últimos anos, com destaque para 2011, com produção significativa de seis trabalhos, caindo para quatro em 2012, ainda assim, em maior número em relação aos anos anteriores. Nota-se que a produção média nos nove primeiros anos (1995 a 2003) foi menor que um trabalho por ano 
$(0,67)$, já nos anos seguintes (2004 a 2012), este valor é superior a 2 trabalhos por ano $(2,11)$. A Tabela 1 apresenta os dados referentes às IES onde essas pesquisas estão alocadas e o seu grau de titulação acadêmica.

Tabela 1 - Dissertações e teses em Educação Ambiental e Geociências nas IES entre 1981 e 2012

\begin{tabular}{cccc}
\hline Instituições & Dissertações & Teses & Total \\
\hline Unicamp & 8 & 4 & $\mathbf{1 2}$ \\
\hline UFRGS & 3 & 0 & $\mathbf{3}$ \\
UFSC & 1 & 1 & $\mathbf{2}$ \\
UFMG & 1 & 0 & $\mathbf{1}$ \\
Unesp & 1 & 0 & $\mathbf{1}$ \\
UFV & 1 & 0 & $\mathbf{1}$ \\
USP & 1 & 0 & $\mathbf{1}$ \\
UFJF & 1 & 0 & $\mathbf{1}$ \\
UFBa & 1 & 0 & $\mathbf{1}$ \\
UEFS & 1 & 0 & $\mathbf{1}$ \\
UFRJ & 1 & 0 & $\mathbf{1}$ \\
\hline
\end{tabular}

Fonte: Elaborado a partir do EArte.

As onze IES identificadas são públicas, tanto na esfera federal quanto estadual. A distribuição dessas pesquisas indica que o Instituto de Geociências da Unicamp possui o maior número de pesquisas nessa área, com $48 \%$ do total. A Universidade Federal do Rio Grande do Sul (UFRGS) apresenta $12 \%$ das pesquisas, e a Universidade Federal de Santa Catarina (UFSC), 8\%. As instituições que abrigam apenas uma pesquisa dessa natureza somam um total de $32 \%$.

Diante de tais dados é possível afirmar que a Unicamp, seguida da UFRGS e da UFSC possui maior continuidade de pesquisas na interface analisada. Essas instituições tornam-se referência como produtoras de conhecimento, representando as possíveis trajetórias para incorporar e consolidar essa temática nos programas de pós-graduação.

As abordagens pontuais, verificadas na UFMG, Unesp, UFV, USP, UFJF, UFBa, UEFS e UFRJ, apontam para a multiplicação de pesquisas pioneiras em diversos programas de pós-graduação. Essas instituições podem indicar um crescente movimento de reconhecimento da importância da integração da Educação Ambiental nas pesquisas em Geociências, suscitando a incorporação dessa temática em linhas de pesquisas específicas.

Os programas de pós-graduação que abrigam as pesquisas na interconexão entre Educação Ambiental e Geociências a partir dessa coleta de dados são: Geociências; Ensino e História das Ciências da Terra; Geociências e Meio Ambiente; Geografia; Geologia; Educação; Solos e Nutrição de Plantas; Ensino, Filosofia e História das Ciências; Modelagem em Ciências da Terra e do Ambiente.

A análise do grau de titulação acadêmica das pesquisas aponta para a predominância de mestrados, com a produção significativa de 20 dissertações. Foram identificadas apenas cinco teses de doutorado.

A Unicamp se destacou em diversos aspectos, sendo importante ponderar alguns pontos observados. Nessa instituição, houve maior concentração de mestrados e de doutorados, além disso, foi a única a apresentar orientadores que se dedicaram a mais de uma 
pesquisa dessa natureza. Os programas de pós-graduação da UFRGS e da UFSC também demonstram importantes contribuições. Assim, na UFRGS houve a produção de três dissertações, duas delas alocadas no Programa de Pós-Graduação em Geociências, tendo orientações distintas, e uma em Geografia. Na UFSC foi verificada a produção de uma dissertação e uma tese, sendo que ambas estão inseridas no Programa de Pós-Graduação em Geografia, possuindo orientadores distintos. A temática identificada nessas duas pesquisas concerne ao patrimônio geológico e à Geoconservação.

No tocante à distribuição geográfica dessas pesquisas, observa-se certa concordância com os dados apontados pela Capes (BRASIL, 2016) que indicam heterogeneidades quanto ao número de programas de pós-graduação em Geociências nas regiões do Brasil. Assim, a maior concentração ocorre na região Sudeste, seguida do Nordeste, Sul, Norte e Centro-Oeste. Segundo os dados obtidos nessa pesquisa, o Sudeste contém $72 \%$ do total das pesquisas, e o Sul, 20\%. Os outros $8 \%$ restantes são referentes ao Nordeste. As regiões Norte e Centro-Oeste não possuem nenhum trabalho pertencente a esse recorte temático.

A delimitação do contexto educacional ${ }^{4}$ dos trabalhos pode ser observada no Gráfico 2. Esses dados indicam que a maioria das pesquisas estavam associadas ao contexto escolar, com 56\% do total (14 pesquisas). A classificação em não escolar refere-se a $28 \%$ (7 pesquisas). As pesquisas que tratam simultaneamente de contexto escolar e não escolar, e, as de abordagem genérica correspondem a $8 \%$ cada uma ( 2 pesquisas cada).

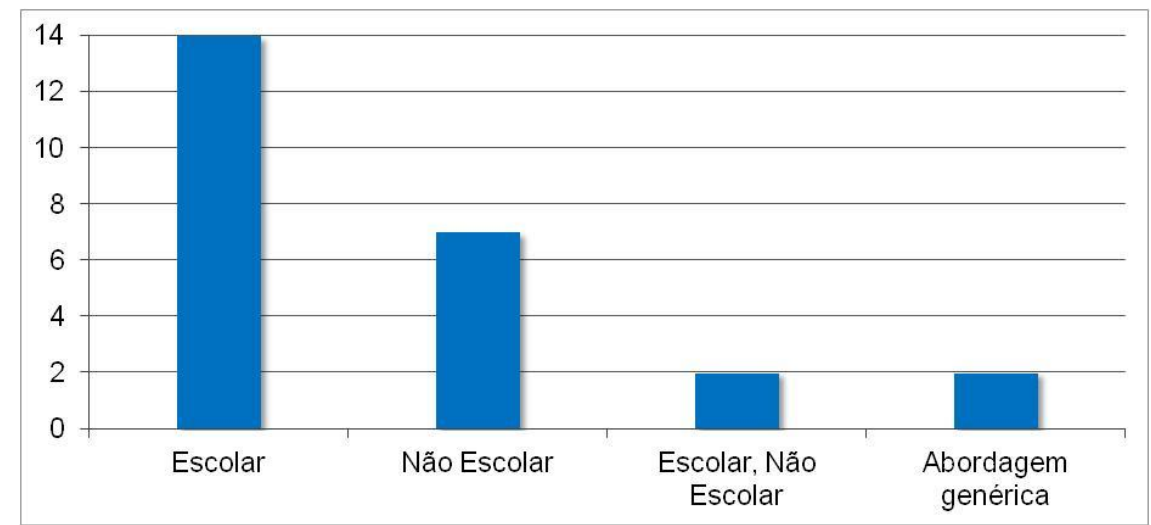

Gráfico 2 - Distribuição de trabalhos de Educação Ambiental e Geociências em relação ao contexto escolar no período de 1995 a 2012

Fonte: Elaborado a partir do EArte.

Os trabalhos referentes ao contexto escolar, e escolar e não escolar, simultaneamente, somam 16 pesquisas e apresentam informações a respeito do nível de ensino em que decorreram. Assim, as modalidades identificadas estão no contexto regular, sendo uma delas também pertencente ao contexto de educação profissional e tecnológica.

As pesquisas de contexto escolar e, escolar e não escolar foram desenvolvidas predominantemente por meio da abordagem genérica em todos os níveis escolares, correspondendo a cinco pesquisas. Identifica-se que o Ensino Fundamental II $\left(5^{\mathrm{a}}\right.$ a $8^{\mathrm{a}}$ série $/ 6^{\circ}$

\footnotetext{
$4 \mathrm{O}$ contexto educacional das pesquisas foi definido pelo projeto EArte de acordo com seus critérios metodológicos. Dessa forma, as pesquisas foram classificadas como não escolar, escolar e como abordagem genérica. Quando se constituem em espaços de educação não formal ou informal, classificam-se como contexto não escolar. Os espaços de educação formal são identificados como contextos escolares. Algumas pesquisas podem se enquadrar nessas duas categorias simultaneamente, sendo, portanto, uma abordagem escolar e não escolar. Por fim, a abordagem genérica é identificada por pesquisas que se relacionam ao fenômeno educativo sem se referir especificamente a qualquer espaço ou nível educacional.
} 
ao $9^{\circ}$ ano) foi adotado em quatro pesquisas. As outras modalidades predominantes foram o Fundamental I ( $1^{\mathrm{a}}$ a $4^{\mathrm{a}}$ série $/ 1^{\mathrm{o}}$ a $5^{\mathrm{o}}$ ano $)$ e o Ensino Superior, apresentando dois trabalhos em cada. O Ensino Médio, Educação de Jovens e Adultos e Educação Profissional e Tecnológica possuíam apenas um trabalho em cada modalidade.

As áreas curriculares ${ }^{5}$ identificadas nas fichas descritoras das pesquisas de contexto escolar, e escolar e não escolar, apresentaram grande diversidade, reforçando o caráter interdisciplinar e abrangente das Geociências. As áreas curriculares observadas foram: Ciências Geológicas, Ciências Agrárias, História, Geografia e Biologia. As áreas de Ciências Naturais e Geografia foram compartilhadas em três pesquisas. Além disso, em uma mesma investigação houve a adoção das áreas de Artes, Ciências Naturais, Geografia, História e Língua Portuguesa. Porém, quatro trabalhos foram classificados como de âmbito geral pelo EArte, e em uma pesquisa não há o registro de qual seu contexto escolar.

\section{Caminhos percorridos}

As pesquisas pioneiras que inseriram a perspectiva das Geociências na Educação Ambiental presentes no banco de dados do Projeto EArte foram analisadas tendo em vista os desafios dessa área emergente e as contribuições advindas de seus autores para delimitar suas trajetórias de pesquisas. Assim, a Educação Ambiental foi referida em diversos contextos nos trabalhos, considerando o embasamento teórico, objetivos, metodologias, resultados, e até mesmo quando a pesquisa indica a necessidade de desenvolvimento de projetos futuros em Educação Ambiental em determinada área de estudo.

Os resumos disponibilizados pelo EArte foram analisados qualitativamente e, a partir das informações que emergiram desses materiais, optou-se por realizar uma classificação das pesquisas, considerando seus pontos de convergências. Assim as três categorias temáticas criadas foram: Pesquisas em Geociências como contribuição a projetos de Educação Ambiental (categoria 1); Divulgação das Geociências (categoria 2); Dimensão escolar e conteúdos Geocientíficos (categoria 3).

\subsection{Pesquisas em Geociências como contribuição a projetos de Educação Ambiental}

Essa categoria reúne quatro pesquisas pelas quais foi possível observar a relevância dos conhecimentos em Geociências para contribuir com ações de Educação Ambiental As pesquisas referidas interpretam a dinâmica do meio físico e, a partir disso, reconhecem a necessidade de utilizar esse conhecimento para a sensibilização e conscientização da população para a conservação da natureza, com ênfase na resolução da degradação ambiental.

Nesse sentido, a Educação Ambiental emerge dos resultados obtidos pela análise física do ambiente, por meio de estudos de impacto ambiental, diagnósticos ambientais e análises de bacias hidrográficas. As análises orientam sua interpretação muitas vezes a partir da interação homem/ambiente e das transformações da paisagem, promovendo reflexões sobre as fragilidades inerentes àquele ambiente e sua relação com o uso e ocupação do solo.

As áreas naturais em que os trabalhos foram desenvolvidos passavam por mudanças paisagísticas, como verificado na pesquisa realizada na área do cerrado de Lagoa Santa (MG),

\footnotetext{
5 A classificação dos trabalhos em áreas curriculares pelo Projeto EArte corresponde ao curso ou disciplina curricular em que determinada pesquisa do contexto escolar se desenvolveu. Além das classificações referentes às disciplinas e/ou cursos (por exemplo, Matemática, Turismo, Ciências Biológicas, dentre outros), as pesquisas podem ser classificadas como de âmbito geral quando não há referência a uma área específica, ou o tema ambiente é tratado genericamente. Além disso, podem ser classificadas como "outra" quando não há indicação nas fichas do projeto EArte e quando as áreas não são indicadas.
} 
(CARVALHO, 1995). Diante da análise física do lugar e da percepção dos moradores sobre essas transformações, a autora ressalta a importância de programas de Educação Ambiental para sua preservação.

Ambientes específicos como sistemas de dunas foram tema de pesquisa na região do litoral norte do Rio Grande do Sul. Portz (2008) sistematizou o diagnóstico dessa área, com enfoque para a fragilidade e os impactos nesses sistemas. Assim, para além das propostas de conciliação do uso das praias com a conservação das dunas a partir do Plano de Manejo, a autora reforça a necessidade de desenvolvimento de projetos de Educação Ambiental que devem proporcionar a divulgação de informações para a sensibilização e mudança de postura da população.

No que diz respeito à escala da bacia hidrográfica destacam-se os trabalhos de Leal (2000) e Rodrigues (2003). O primeiro autor centra-se na análise das possibilidades advindas dos espaços de gestão das águas para a intervenção e resolução da degradação ambiental. Em Rodrigues (2003), o estudo dos impactos urbanos na bacia hidrográfica subsidiou o desenvolvimento de um programa de Educação Ambiental considerando a participação de professores para sua elaboração. Em ambos os casos é ressaltado o caráter participativo da gestão das águas, pois a escala da bacia hidrográfica integra diversas questões inerentes à vida das pessoas e ao ambiente local.

O estudo da bacia hidrográfica é recorrente em pesquisas de Geociências por se constituir em uma unidade natural de análise, permitindo estabelecer as inter-relações existentes entre os elementos diversos da paisagem e seus processos (BOTELHO, 1999). Ideal para o planejamento territorial, a bacia hidrográfica permite uma visão sistêmica e holística de todos os elementos e processos que atuam e atuaram na superfície drenada em questão. Além disso, a instalação dos Comitês de Bacias Hidrográficas propicia situações e espaços para a participação da comunidade (JACOBI, 2011).

De um modo geral, essa categoria revela a ênfase no conhecimento acerca do meio físico para contribuir com ações de Educação Ambiental. Essa abordagem propicia a inclusão dos aspectos físicos em interação com os diversos sistemas da Terra nas estratégias de conservação. Entretanto, não trazem uma abordagem relativa ao tempo geológico e à dinâmica de transformação da paisagem, mas compreende uma transformação imediatista que contempla o homem como agente de transformação. Nesse caso, distancia-se de um ponto central das Geociências que é a dimensão do tempo. Há um foco nas transformações mais recentes, o que pode levar a uma percepção reducionista e não complexa da contribuição do conhecimento geológico que é visto como base de diagnóstico dos problemas ambientais.

Observam-se algumas convergências quanto aos caminhos utilizados nas pesquisas em Geociências para interpretar o meio físico como estudos de impactos ambientais, análise de fragilidade e vulnerabilidade, a elaboração de Plano de Manejo, o estudo de bacias hidrográficas e a interpretação das transformações paisagísticas que privilegiaram a incorporação de abordagens próprias da Educação Ambiental.

Destacam-se alguns princípios relativos à Educação Ambiental que foram apontados pelos resumos como a sensibilização e divulgação de informação para mudanças de postura e para a conservação do ambiente, a análise crítica do lugar e o fortalecimento da gestão participativa em bacias hidrográficas. 


\subsection{Divulgação das Geociências}

A divulgação das Geociências pode ser entendida de forma similar à divulgação científica, que, como destacou Mansur (2009, p.64) procura ampliar o acesso ao conteúdo científico "por meio da decodificação de termos pouco usuais para uma linguagem acessível ao público leigo".

Foram reconhecidas sete pesquisas que procuram estimular a inserção de conteúdos geocientíficos em ambientes escolares e não escolares, através de estratégias de divulgação.

Bernsmüller (2005) e Armesto (2011) se propuseram a desenvolver materiais didáticos convergindo para a divulgação das Geociências. No primeiro caso, o material propicia uma maior divulgação dos conhecimentos sobre a Antártica. Já no segundo, a pesquisadora baseiase no reconhecimento da geodiversidade para subsidiar ações de Educação Ambiental em abordagens multidisciplinares, resultando na elaboração de materiais paradidáticos.

Notam-se trabalhos que não se restringem ao ambiente escolar nem à produção de material didático como a contribuição de Souza (2005) em sua tese a respeito da presença de temas, ou notícias geocientíficas, em uma televisão pública e regional, com pauta aberta à participação da comunidade. Além de analisar a consistência e os conteúdos das notícias, foi possível compreender sua relação com a comunidade, expondo uma demanda por assuntos geocientíficos e relacionados ao ambiente local. O diálogo com a Educação Ambiental é reforçado no tratamento de temas locais, associados à questão da sustentabilidade.

Vieira (2005) aborda uma reflexão a respeito das concepções de profissionais da área da saúde que trabalham como agentes comunitários em áreas de risco ambiental. Por tratar-se de profissionais que atendem e orientam os moradores do bairro para as questões de saúde, suas concepções relativas ao meio físico apontam para a necessidade de maior formação desses profissionais em conteúdos geocientíficos.

Outras contribuições, como as de Moreira (2008), Covello (2011) e Morais (2012) chamam a atenção para os espaços não formais de educação. As duas primeiras pesquisas se desenvolvem em Unidades de Conservação (UCs) e a última, no Museu de Ciências da Terra em Viçosa (MG). Moreira (2008) e Covello (2011) centram-se na temática do patrimônio geológico e da geodiversidade em UCs, lançando olhar para comunidades, professores e turistas inseridos nessas regiões. Reconhecer e divulgar a geodiversidade a partir da contribuição da Educação Ambiental aproxima-se muitas vezes dos princípios da interpretação ambiental, possibilitando a criação de roteiros de visitação turística com ênfase na geodiversidade. No caso de Morais (2012), o espaço do museu para a divulgação das Ciências da Terra é valorizado a partir da comunidade que mantém forte interação e que se apropria deste espaço.

Nesta categoria há predomínio de estratégias que visam à divulgação do saber geocientífico em diversos contextos, apresentando reflexões sobre a importância desse conhecimento para que essas informações sejam compreendidas pela sociedade, entendendo a dinâmica física do ambiente em interação com a dinâmica social e cultural.

As convergências entre a Educação Ambiental e as Geociências estão pautadas na preocupação em como elaborar materiais didáticos em Geociências, ou como criar estratégias de divulgação em ambientes não escolares (UCs, museus e mídia).

No campo escolar, os materiais didáticos e paradidáticos abrangem questões gerais, apresentando conteúdos que não estão diretamente relacionados com o lugar. Nos contextos não escolares, a divulgação das Geociências se pauta na preparação de atividades educativas e roteiros geoturísticos que conciliam o turismo na natureza com atividades didáticas a partir do lugar visitado, relacionando conteúdos geocientíficos aos aspectos observados em campo. 
Nas abordagens relacionadas à comunicação pública, observa-se a preocupação da veiculação de informações em contextos práticos, como no papel dos agentes comunitários de saúde em orientar moradores de áreas de risco ambiental. E também no caso da inserção desses conteúdos na televisão, revelando a demanda por notícias e informações que abranjam as Geociências, valendo-se do papel da televisão como importante meio de comunicação, o que possibilita maior alcance na divulgação.

Portanto, essas propostas contribuem com metodologias e ferramentas para promover um maior alcance da informação em Geociências, revelando-se muitas vezes em um saber prático e relacionado ao ambiente local. Em alguns casos essa divulgação vem ao encontro da Geoconservação, que consiste no reconhecimento da importância da geodiversidade e do patrimônio geológico e da necessidade de se pensar em práticas de conservação da natureza que incluam esses elementos.

Nesse sentido, as aproximações entre Geociências e Educação Ambiental decorreram da preparação de materiais didáticos, roteiros interpretativos e estratégias de comunicação geocientífica centrados em divulgar um saber prático, tendo como preocupação a informação, porém, sem que haja uma formação mais específica e contextualizada.

\subsection{Dimensão escolar e conteúdos geocientíficos}

O predomínio das pesquisas em espaços formais de educação revela o esforço da comunidade acadêmica em ampliar a presença de conteúdos geocientíficos na educação básica no Brasil. Assim, as 13 pesquisas aqui analisadas recorrem a algumas estratégias que têm se mostrado eficientes na incorporação e fortalecimento dos conteúdos geocientíficos no ensino. Além disso, partem dos pressupostos da Educação Ambiental Crítica nas estratégias educativas. As pesquisas analisadas têm como público-alvo professores e alunos do Ensino Básico, da Educação de Jovens e Adultos, e dos Ensinos Técnico e Superior.

Nessa categoria observou-se uma multiplicidade de contextos de pesquisas que foram agrupadas em: alunos como público-alvo e professores como público-alvo.

\subsubsection{Pesquisas que têm os alunos como público-alvo}

Foram observadas seis investigações apresentando como público-alvo os alunos. A origem dessas pesquisas se deve a professores que atuam como pesquisadores diante de uma problemática vivenciada no cotidiano escolar. E, em outros casos, de pesquisadores que se aproximam dos professores para analisar o processo de ensino-aprendizagem e propor inovações e novas perspectivas nessa interação entre a Educação Ambiental e as Geociências.

Destacam-se as contribuições de Tamaio (2000) e Zanini (2011), que incorporaram abordagens inovadoras em sala de aula inserindo temas socioambientais e conteúdos geocientíficos em suas dinâmicas. No primeiro caso, o professor pesquisador examinou sua atuação em aula incorporando a metodologia do trabalho de campo. Assim, inseriu questões a respeito do entorno da escola como contributo para superar a visão romântica que os alunos possuíam da natureza, alcançando uma visão socioambiental. Já em Zanini (2011), a pesquisa teve como foco as inovações curriculares proporcionadas pela introdução de temas significativos, contextualizando o ensino de química por meio do ambiente terrestre. A autora reforça assim a interdisciplinaridade entre a Química e as Geociências, além de contribuir para o desenvolvimento de uma postura socioambiental nos alunos.

A metodologia do trabalho de campo revelou-se recorrente ao proporcionar um ensino significativo, contextualizado e interdisciplinar aos alunos, mantendo relação estreita com a Educação Ambiental. Melo (2011) traz à tona a narrativa de alunos que experienciaram 
atividades de campo com ênfase no olhar geocientífico, para compreensão da realidade local. A dissertação de Melo (2012) se alicerçou no papel do trabalho de campo desenvolvido na semana de recepção de calouros ingressantes nos cursos de Bacharelado em Geologia e Licenciatura em Geociências e Educação Ambiental na USP. A presença dessa metodologia desde a entrada dos alunos nesses cursos refletiu-se na importância para a formação inicial desses profissionais, conduzindo sua prática futura no ensino e em projetos de Educação Ambiental.

No tocante ao ensino de Ciências para a formação de um cidadão preocupado com a responsabilidade socioambiental, Guimarães (2010), que teve sua pesquisa desenvolvida no âmbito do Ensino Superior em Biologia, desenvolve de forma colaborativa uma unidade didática com a inclusão de conteúdos da Ciência do Sistema Terra, contribuindo para a compreensão sistêmica da Terra e estimulando discussões a respeito dos aspectos socioculturais, ambientais, políticos e econômicos num contexto de enfrentamento da crise ambiental.

A utilização de recursos de sensoriamento remoto por Almeida (2012) possibilitou uma maior aproximação dos alunos com seu contexto local em interação com outras escalas, favorecendo o pensamento crítico e reflexivo e, além disso, alcançando aprendizagens relativas à cartografia.

As estratégias de ensino de Geociências que incorporaram concepções da Educação Ambiental com foco nos alunos prescindem da utilização de diversas estratégias educativas já consagradas no ensino da dinâmica física do ambiente. Exemplo disso foram os trabalhos de campo e uso de imagens de satélite, que são explorados de forma a proporcionar um olhar mais dinâmico sobre o ambiente, fundamentados nos princípios da educação ambiental da contextualização, análise crítica do ambiente, perspectiva participativa e integradora, dialogicidade, interdisciplinaridade e procura de enfrentamento de problemas socioambientais locais.

Interessante notar que os resultados obtidos nessas pesquisas apontam para a relevância dessas abordagens em Geociências proporcionando a visão sistêmica da Terra e a análise dos problemas socioambientais locais, numa perspectiva de Educação Ambiental Crítica. Essas situações didáticas se mostraram possíveis de serem abordadas no contexto do ensino superior em Ciências Geológicas e Biologia, Educação de Jovens e Adultos, e Ensino Fundamental I ( $1^{\mathrm{a}}$ a $4^{\mathrm{a}}$ série $/ 1^{\mathrm{o}}$ ao $5^{\mathrm{o}}$ ano) e II $\left(5^{\mathrm{a}}\right.$ a $8^{\mathrm{a}}$ série $/ 6^{\circ}$ ao $9^{\circ}$ ano $)$, sendo que sua centralidade está na formação desses indivíduos, diferentemente de uma concepção informativa.

\subsubsection{Pesquisas que têm como público alvo os professores}

As análises com foco nos professores foram identificadas em oito pesquisas. Os trabalhos apontam caminhos para a inserção dos conteúdos de Geociências no ensino formal e nos projetos de Educação Ambiental, considerando estudos de caso desenvolvidos a partir de oficinas e cursos de formação continuada de professores em exercício. Assim, muitas propostas avaliam as concepções dos profissionais envolvidos nos cursos, proporcionando orientações para processos formativos futuros, demonstrando o alcance oportunizado pela inserção de conteúdos geocientíficos.

Nessa perspectiva se enquadram os trabalhos de Guimarães (1999), Mattosinho (2000) e Santos (2011). A primeira autora faz reflexões sobre um projeto de Educação Ambiental desenvolvido por professores tendo como cenário a dinâmica da bacia hidrográfica, com maior ênfase nos trabalhos de campo realizados, refletindo sobre seu potencial educativo. Mattosinho (2000) tem como cenário uma Unidade de Conservação, lançando olhar sobre os 
professores das escolas da região e a necessidade de se aprofundarem sobre as possibilidades educacionais na área de preservação ambiental, com enfoque também para uma educação para conservação. Já em Santos (2011), há uma análise específica sobre os conhecimentos de professores que ministram a disciplina de Geociências no Curso Técnico em Meio Ambiente, constatando uma fragilidade no cumprimento do conteúdo programado com consequentes prejuízos na formação desses técnicos em relação aos aspectos das Ciências da Terra.

O escopo da dissertação de Biondo (2012) em compreender a relação entre o espaço geográfico e a Educação Ambiental se deu por meio da análise da produção geográfica (teses, dissertações e artigos) que dialoga com a Educação Ambiental, e dos materiais didáticos em Educação Ambiental destinados aos professores que tangenciam a Geografia. Assim, a análise das produções geográfica em meio acadêmico e educativo permitiu à autora dialogar e relacionar a educação e o ambiente como possibilidade de leitura de mundo.

Em algumas abordagens há uma maior preocupação com a formação continuada de professores em exercício, incluindo Panzeri (2006), Piranha (2006), Santos (2006) e Lobo (2009). A primeira autora dá destaque à possibilidade de os professores atuarem como multiplicadores. Em sua formação foi priorizado o estudo do meio como metodologia para a contextualização e integração de temas na perspectiva da Educação Ambiental, oportunizando também um estímulo às inovações curriculares onde esses professores atuam e podem dar continuidade aos projetos. Lobo (2009) centra-se na preparação de monitores para se dedicarem a um ensino significativo e no contexto da agroecologia na realidade das Escolas de Famílias Agrícolas.

Por fim, nas teses de Piranha (2006) e Santos (2006), as contribuições vão ao encontro de valorizar trabalhos de campo e estudo do meio para despertar a identidade e para o (re)conhecimento do lugar. Dessa maneira, a formação continuada de professores proporciona a inserção desses novos saberes no ensino e valorizam o desenvolvimento de projetos em educação socioambiental, no contexto local e global, alcançando o que Piranha (2006) destacou como um cidadão planetário ou, como Santos (2006) apontou, professores críticos e reflexivos.

Nesse aspecto observam-se muitas contribuições que inserem a participação dos professores nas propostas. Nas formações desenvolvidas, o professor se inclui na elaboração de projetos de Educação Ambiental, visando sua continuidade para além do desenvolvimento da pesquisa, fortalecendo sua autonomia e responsabilidade.

O professor é reconhecido pelo seu papel de articular temas e envolver os alunos com os conteúdos geocientíficos e as questões socioambientais locais. Essas pesquisas apresentam assim as potencialidades de abordagens locais lançando olhar sobre as UCs, e temas como a agroecologia, o desenvolvimento da cultura da sustentabilidade e a relação local e global através das diferentes escalas de atuação. Dessa maneira pode-se observar a relação esperada entre as Geociências e a Educação Ambiental em uma concepção crítica. Nesse sentido, o ensino de Geociências se relaciona com a dinamicidade da natureza, no contexto do tempo geológico, e a reflexão sobre as interações entre os diversos sistemas, incluindo o social.

A centralidade na formação de professores nessa interface alavanca a abordagem desses conteúdos nas escolas, desenvolvendo caminhos para uma real apropriação dos conhecimentos em Geociências, possibilitando sua articulação em sala de aula e em projetos de Educação Ambiental. 


\section{Considerações finais}

Os 25 trabalhos selecionados a partir do Projeto EArte que estão na interface da Educação Ambiental com as Geociências são ainda pouco representativos do ponto de vista quantitativo da produção acadêmica brasileira em Educação Ambiental. Porém, apresentam iniciativas precursoras e que marcam as diversas possibilidades inerentes a essa interface. A análise desse acervo e as convergências identificadas revelaram os percursos de uma área de interação ainda em formação que requer consolidação de sua identidade e reconhecimento acadêmico.

Alguns espaços institucionais constituem papel importante nesse contexto, como a Unicamp, considerada referência em pesquisas nessa temática. Outras instituições também têm colaborado com esse quadro, como a UFRGS e a UFSC, ainda que não tenham linhas de pesquisas ou programas de pós-graduação específicos. Não foi observado um aumento gradual de trabalhos, mas constatou-se que nos últimos nove anos (2004 a 2012) há uma média maior de 1,44 trabalhos por ano em comparação com o período de 1995 a 2003 . Em relação à distribuição espacial dessas pesquisas houve uma desigualdade entre as regiões do Brasil, com predomínio de $70 \%$ dos trabalhos na região Sudeste.

A recorrência de $56 \%$ dos trabalhos em contexto escolar é muito relevante, considerando que a escola é local de aprendizado por excelência. Destaca-se assim a necessidade e a possibilidade de inclusão desses conteúdos na educação básica e também no ensino técnico e superior, permitindo abordagens interdisciplinares, centradas na apropriação desse saber para lidar com a complexidade socioambiental.

O contexto não escolar também apresenta potencialidades, representando $29 \%$ das pesquisas referentes aos espaços de educação não formal e informal, como museus, UCs e ambientes midiáticos. Nesse caso as análises indicaram que as Geociências são valorizadas no contexto da proposição de projetos de Educação Ambiental tanto em ambiente escolar como não escolar, partindo dos aspectos do meio físico e do lugar. No entanto, esse foco no diagnóstico ambiental, sem considerar a dinâmica espacial e temporal das transformações na paisagem, pode levar a um reducionismo do uso do conhecimento geológico para contribuir com a interpretação do meio e para os projetos em Educação Ambiental. Além disso, um viés informativo nas ações de divulgação das Geociências reduz esse conhecimento a um aspecto técnico e conceitual, restringindo as possibilidades de interpretação do meio socioambiental local relacionado com os conhecimentos em Geociências.

As metodologias das pesquisas variaram principalmente de acordo com os eixos temáticos propostos. Na categoria 1 (Pesquisas em Geociências como contribuição a projetos de Educação Ambiental), as metodologias eram próprias para o diagnóstico do meio físico, e algumas incluíram a análise de comunidades do entorno. A categoria 2 (Divulgação das Geociências) também apresentou diagnósticos do meio físico e social para a elaboração de materiais didáticos, de roteiros e percursos geoturísticos, além de abranger a valorização e inserção desses conteúdos em ambientes midiáticos e em exposições museológicas. A categoria 3 (Dimensão escolar e temas geocientíficos) concentrou a maior parte dos trabalhos que efetivamente desenvolveram projetos escolares de Educação Ambiental. Nesse caso a metodologia descrita nos resumos refere-se à pesquisa-ação, com ênfase nos trabalhos de campo, além de uso de recursos didáticos como imagens de satélite, aulas dialogadas com abordagem no contexto local (bacias hidrográficas, estudo do lugar).

A análise dos resumos indicou alguns aspectos que subsidiaram a identificação das concepções de Educação Ambiental de acordo com Silva (2007), considerando as tipologias de Educação Ambiental Conservadora, Pragmática e Crítica. Porém, como destacou a autora, 
"devido à própria complexidade da Educação Ambiental, não é tarefa fácil identificar onde termina uma dimensão e onde começa outra" (SILVA, 2007, p. 96).

As duas primeiras categorias identificadas neste trabalho, que se referem em grande parte a contextos não escolares, puderam ser agrupadas na concepção de Educação Ambiental Pragmática. Foi possível observar os seguintes aspectos destacados por Silva (2007, p. 97): a "relação direta entre informação e mudança de comportamento" e "resolução dos problemas ambientais pela ciência e tecnologia". As pesquisas recorriam a estratégias pertinentes à resolução da problemática ambiental, ao desenvolvimento de estratégias de educação ambiental pautadas na informação para mudanças de postura e no desenvolvimento de programas de educação para a preservação ambiental.

Assim, os conhecimentos geocientíficos são a base do entendimento do meio físico, tomado na forma de diagnóstico do meio. Os dados são levantados de forma estática, sem consideração das dimensões espaço e tempo para compreensão da dinâmica física terrestre. Os conhecimentos não se constituem como objeto de aprendizagem, revelando-se como informações pontuais e locais.

Entretanto, pesquisas dessas categorias que continham aspectos de interface entre a Educação Ambiental Pragmática e Crítica evidenciaram a postura de promover a participação de comunidades locais em estratégias de divulgação, interpretação e sensibilização quanto à geodiversidade.

Os trabalhos desenvolvidos em ambiente escolar, na terceira categoria, representaram predominantemente uma concepção de Educação Ambiental Crítica, em que as abordagens inserem aspectos apontados por Silva (2007, p. 97) como "interdisciplinaridade na produção do conhecimento", "incentivo à formação de valores e atitudes direcionados pela ética e justiça ambiental", "fortalecimento da sociedade civil; ênfase na participação coletiva", "exploram-se potencialidades ambientais locais/regionais", "estudo do meio". Esses aspectos são apresentados nos resumos referindo-se a programas de Educação Ambiental que inserem a análise crítica do entorno, o trabalho colaborativo com moradores locais e/ou professores na elaboração e desenvolvimento das estratégias.

Nessa perspectiva, os conhecimentos geocientíficos são apreendidos como entendimento da dinâmica do planeta e são reconhecidos como parte de uma abordagem formativa complexa.

As relações tecidas entre as pesquisas em Geociências e Educação Ambiental têm configurado estratégias de ensino e divulgação das Geociências. Nos casos em que mais se aproximam da Educação Ambiental Crítica, proporcionam um saber integrado e prático, em relação à conservação da natureza, do entendimento do funcionamento do ambiente local e global, e na formação de cidadãos que compreendem a dinâmica do planeta, em interação com seu contexto sócio-histórico, valorizando abordagens colaborativas e interdisciplinares.

O fomento da participação de atores sociais, como comunidades, professores e alunos, na elaboração e desenvolvimento de projetos de Educação Ambiental a partir dos saberes do meio físico enriquece e fortalece a aprendizagem da complexa dinâmica planetária e suas interações com a esfera humana e a responsabilidade socioambiental.

Para o campo da Educação Ambiental, essa categorização aponta para a importância da inserção da visão sistêmica da Terra em seus projetos. A perspectiva do ensino de Geociências de forma interdisciplinar contribui com a problematização das questões locais em interação com o global, reforçando a importância dos diversos saberes na formação de indivíduos críticos e propositivos. Nesse sentido a inserção das Geociências nas pesquisas foi relevante, porém a abordagem desenvolvida na terceira categoria (Dimensão escolar e 
conteúdos geocientíficos) foi a maior contribuição para a apropriação desse saber e a articulação com a Educação Ambiental Crítica.

\section{Referências}

ALMEIDA, R. S. Do imaginário ao real: potencial pedagógico da imagem de satélite em ações de educação ambiental ligadas ao Parque Municipal da Serra do Periperi, Vitória da Conquista-Bahia. 2012. 95 f. Dissertação (Mestrado em Ciências Ambientais) - Universidade Estadual de Feira de Santana, Feira de Santana, 2012.

ARMESTO, R. C. G. Cadernos de temas geológicos para Educação Ambiental: uma contribuição das Geociências para programas de Educação Ambiental no ensino fundamental. 2011. 250 f. Dissertação (Mestrado em Geologia) - Universidade Federal do Rio de Janeiro, Rio de Janeiro, 2011.

BACCI, D. C. Ensino de Geociências no contexto escolar: múltiplas relações com a Educação Ambiental. In: BACCI, D. C. (Org.). Geociências e Educação Ambiental. Curitiba: Ponto Vital, 2015. p. $167-198$.

BACCI, D. C.; BOGGIANI, P. C. O currículo do curso de Licenciatura em Geociências e Educação Ambiental - Ligea-USP: formação de professores com visão sistêmica do Planeta Terra. In: BACCI, D. C. (Org.). Geociências e Educação Ambiental. Livro eletrônico. Curitiba: Ponto Vital, 2015. p. 1233.

BERNSMÜLLER, L. Implementação de um protótipo de uma aplicação multimídia sobre a Ilha Rei George, Antártica. 2005. 84 f. Dissertação (Mestrado em Geociências) - Universidade Federal do Rio Grande do Sul, Porto Alegre, 2005.

BIONDO, E. C. Ambiente e geografia: um estudo da relação entre espaço geográfico e educação ambiental. 2012. 142 f. Dissertação (Mestrado em Geografia) - Universidade Federal do Rio Grande do Sul, Porto Alegre, 2012.

BOTELHO, R. G. M. Planejamento ambiental em microbacia hidrográfica. In: GUERRA, A. J. T.; SILVA, A. S.; BOTELHO, R. G. M. (Orgs.). Erosão e conservação dos solos: conceitos, temas e aplicações. Rio de Janeiro: Bertrand, 1999. p. 269-300.

BRASIL. Conselho Nacional de Educação. Resolução n ${ }^{\circ}$ 2, de 15 de junho de 2012. Estabelece as Diretrizes Curriculares Nacionais para a Educação Ambiental. Diário Oficial [da] República Federativa do Brasil, Brasília, DF, 18 jun. 2012. p 70. Disponível em: 〈https://goo.gl/5XbDS9>. Acesso em: 27 out. 2016.

BRASIL. Ministério da Educação. Coordenação de Aperfeiçoamento de Pessoal de Nível Superior. Documento de Área 2016: Geociências. Brasília, DF, 2016. Disponível em: 〈https://goo.gl/ATm859>. Acesso em: 9 mar. 2017.

CARNEIRO, C. D. R. et al. Ciência do sistema terra e o entendimento da "máquina" planetária em que vivemos. Geonomos, Belo Horizonte, v. 13, n. 1-2, p. 11-18, 2005. Disponível em: <https://goo.gl/FUF4x4>. Acesso em: 6 mar. 2017.

CARVALHO, P. G. S. O cerrado de Lagoa Santa - MG: transformações e a percepção do homem. 1995. 183 f. Dissertação (Mestrado em Geografia) - Universidade Federal de Minas Gerais, Belo Horizonte, 1995.

COMPIANI, M. Geologia/Geociências no Ensino Fundamental e a formação de professores. Geologia USP: Publicação Especial, São Paulo, v. 3, p. 13-30, 2005. Disponível em: 〈https://goo.gl/vQwipQ〉. Acesso em: 27 out. 2016. 
COMPIANI, M. (Org.). Ribeirão Anhumas na escola: projeto de formação continuada elaborando conhecimentos escolares relacionados à ciência, à sociedade e ao ambiente. Curitiba: CRV, 2013. v. 1.

COMPIANI, M. Ribeirão Anhumas na escola: pesquisa colaborativa entre a escola e universidade gerando conhecimentos contextualizados e interdisciplinares. Curitiba: CRV, 2015. v. 1.

CORDANI, U. G. As Ciências da Terra e a mundialização das sociedades. Estudos Avançados, São Paulo, v. 9, n. 25, p. 13-27, 1995. Disponível em: 〈https://goo.gl/D55rXf〉. Acesso em: 27 out. 2016.

COVELLO, C. A paisagem de Itapema: estudo da geodiversidade para a educação ambiental e o geoturismo. 2011. 173 f. Dissertação (Mestrado em Geografia) - Universidade Federal de Santa Catarina, Florianópolis, 2011.

CRUTZEN, P. J.; STOERMER, E. F. The "Anthropocene”. Global Change Newsletter, Stockholm, n. 41, p. 17-18, 2000.

ESCOLA DE ARTES, CIÊNCIAS E HUMANIDADES. Licenciatura em Ciências da Natureza. São Paulo: Universidade de São Paulo, 2012. Disponível em: <https://goo.gl/SjXgB >. Acesso em: 22 mar. 2017.

FINLEY, F.D; NAM, Y.; OUGHTON, J. Earth systems science: an analytic framework. Science Education, Hoboken, v. 95, n. 6, p. 1066-1085, 2011.

GUIMARÃES, E. M. A. Trabalhos de campo em bacias hidrográficas: os caminhos de uma experiência em Educação Ambiental. 1999. 172 f. Dissertação (Mestrado em Geociências) Universidade Estadual de Campinas, Campinas, 1999.

GUIMARÃES, M. D. M. Características de uma unidade didática baseada em uma visão sistêmica do funcionamento do planeta Terra aplicada a estudantes ingressantes do ensino superior. 2010. 146 f. Dissertação (Mestrado em Ensino, Filosofia e História das Ciências) - Universidade Federal da Bahia, Salvador, 2011.

JACOBI, P. (Coord.). Aprendizagem social: diálogos e ferramentas participativas: aprender juntos para cuidar da água. São Paulo: IEE/Procam, 2011. Disponível em: 〈https://goo.gl/1yHrwQ〉. Acesso em: 27 out. 2016.

LEAL, A. C. Gestão das águas no Pontal do Paranapanema - São Paulo. 2000. 279 f. Tese (Doutorado em Geociências) - Universidade Estadual de Campinas, Campinas, 2000.

LIMA, M. J. A. Ecologia humana: um estudo no Nordeste brasileiro. 1981. 206 f. Dissertação (Mestrado em Educação) - Universidade Federal de Minas Gerais, Belo Horizonte, 1981.

LOBO, L. M. Solos e alternâncias educativas: pesquisa-ação na formação de educadores. 2009. $121 \mathrm{f}$. Dissertação (Mestrado em Solos e Nutrição de Plantas) - Universidade Federal de Viçosa, Viçosa, 2009.

MANSUR, K. Projetos educacionais para a popularização das Geociências e para a geoconservação. Geologia USP: Publicação Especial, São Paulo, v. 5, p. 63-74, 2009. Disponível em: <https://goo.gl/iXiYJv>. Acesso em: 22 mar. 2017.

MATTOSINHO, M. A educação para conservação do ambiente na área de proteção ambiental da região de Sousas e Joaquim Egídio, Campinas, SP. 2000. 212 f. Dissertação (Mestrado em Geociências) - Universidade Estadual de Campinas, Campinas, 2000. 
MELO, N. P. Trabalhos de campo na semana de recepção de calouros no instituto de Geociências/USP: institucionalização do ensino de Geociências (1972-2012). 2012. 188 f. Dissertação (Mestrado em Educação) - Universidade de São Paulo, São Paulo, 2012.

MELO, V. R. O. Produção de textos narrativos e descritivos por meio de atividades geocientíficas com alunos do ensino fundamental II. 2011. 155 f. Dissertação (Mestrado em Ensino e História de Ciências da Terra) - Universidade Estadual de Campinas, Campinas, 2011.

MORAIS, E. H. M. Os museus de ciência como territórios da Educação Ambiental: o caso do Museu de Ciências da Terra Alexis Dorofeef, Viçosa (MG). 2012. 132 f. Dissertação (Mestrado em Educação) - Universidade Federal de Juiz de Fora, Juiz de Fora, 2012.

MOREIRA, J. C. Patrimônio geológico em unidades de conservação: atividades interpretativas, educativas e geoturísticas. 2008. 428 f. Tese (Doutorado em Geografia) - Universidade Federal de Santa Catarina, Florianópolis, 2008.

NOBRE, M. C. D. P. A proposição de objetivos para um curso de Física do Meio Ambiente no Rio Grande do Norte: uma questão de análise sistemática. 1981. 160 f. Dissertação (Mestrado em Física) Universidade de São Paulo, São Paulo, 1981.

PANZERI, C. G. Educação Ambiental e itinerários curriculares no cotidiano das séries iniciais do ensino fundamental: contribuições teórico-metodológicas do Projeto Acre 2000 de Educação Ambiental, Rio Branco/AC. 2006. 128 f. Dissertação (Mestrado em Ensino e História de Ciências da Terra) - Universidade Estadual de Campinas, Campinas, 2006.

PERNAMBUCO, M. M. C. A. Ensino de ciências a partir de problemas da comunidade. 1981. $280 \mathrm{f}$. Dissertação (Mestrado em Ensino de Ciências) - Universidade de São Paulo, São Paulo, 1981.

PIRANHA, J. O ensino de Geologia como instrumento formador de uma cultura de sustentabilidade: o projeto Geo-escola em São José do Rio Preto, SP. 2006. 222 f. Tese (Doutorado em Geociências) Universidade Estadual de Campinas, Campinas, 2006.

PIRANHA, J. M.; CARNEIRO, C. D. R. O ensino de geologia como instrumento formador de uma cultura de sustentabilidade. Revista Brasileira de Geociências, São Paulo, v. 39, n. 1, p. 129-137, 2009.

PORTZ, L. C. Contribuição para o estudo do manejo de dunas: caso das praias de Osório e XangriLá, Litoral Norte do Rio Grande do Sul. 2008. 128 f. Dissertação (Mestrado em Geociências) Universidade Federal do Rio Grande do Sul, Porto Alegre, 2008.

PRICE, S. J. et al. Humans as major geological and geomorphological agents in the Anthropocene: the significance of artificial ground in Great Britain. Philosophical Transactions of The Royal Society A, London, n. 369, p. 1056-1084, 2011.

RODRIGUES, B. E. P. F. Impactos no meio físico da bacia hidrográfica do córrego das Almas, Pouso Alegre $(M G)$ : subsídios para a Educação Ambiental. 2003. 125 f. Dissertação (Mestrado em Geociências e Meio Ambiente) - Universidade Estadual Paulista "Júlio de Mesquita Filho", Rio Claro, 2003.

SANTOS, G. R. B. A disciplina Geociências na formação de técnicos ambientais: prospecção de práticas pedagógicas. 2011. 116 f. Dissertação (Mestrado em Ensino e História de Ciências da Terra) Universidade Estadual de Campinas, Campinas, 2011. 
SANTOS, V. M. N. Formação de professores para o estudo do ambiente: projetos escolares e a realidade socioambiental local. 2006. 279 f. Tese (Doutorado em Ensino e História de Ciências da Terra) - Universidade Estadual de Campinas, Campinas, 2006.

SANTOS, V. M. N. Educar no ambiente: construção do olhar geocientífico e cidadania. São Paulo: Annablume, 2011.

SILVA, R. L. F. O meio ambiente por trás da tela: estudo das concepções de educação ambiental nos filmes da TV Escola. 2007. 277 f. Tese (Doutorado em Educação) - Universidade de São Paulo, São Paulo, 2007.

SOUZA, C. M. Geociências, comunicação e cidadania: aspectos da construção de diálogos numa televisão de natureza pública. 2005. 224 f. Tese (Doutorado em Geociências) - Universidade Estadual de Campinas, Campinas, 2005.

TAMAIO, I. A mediação do professor na construção do conceito de natureza: uma experiência de Educação Ambiental na Serra da Cantareira e Favela do Flamengo - São Paulo/SP. 2000. 141 f. Dissertação (Mestrado Geociências) - Universidade Estadual de Campinas, Campinas, 2000.

TOLEDO, M. C. M. et al. Projeto de criação do curso de Licenciatura em Geociências e Educação Ambiental - Instituto de Geociências/USP. Geologia USP: Publicação Especial, São Paulo, v. 3, p. 111, 2005. Disponível em: 〈https://goo.gl/k36m34>. Acesso em: 22 mar. 2017.

UNIVERSIDADE ESTADUAL DE CAMPINAS. O Programa Ensino e História de Ciências da Terra. Campinas, [201-?]. Disponível em: 〈https://goo.gl/9c6qnF>. Acesso em: 21 jul. 2016.

UNIVERSIDADE ESTADUAL PAULISTA. Apresentação: Geociências e Meio Ambiente. Rio Claro, 2016. Disponível em: 〈https://goo.gl/EkQsiL〉. Acesso em: 11 nov. 2016.

VIEIRA, M. P. A. Educação, saúde e ambiente: concepções do meio físico na ação educacional do agente comunitário de saúde junto a moradores em área de risco ambiental. 2005. 158 f. Dissertação (Mestrado em Ensino e História de Ciências da Terra) - Universidade Estadual de Campinas, Campinas, 2005.

ZANINI, S. M. C. Dinâmica natural e ensino de Química para jovens e adultos: saberes e práticas de uma inovação curricular. 2011. 131 f. Dissertação (Mestrado em Ensino e História de Ciências da Terra) - Universidade Estadual de Campinas, Campinas, 2011. 